\title{
Comment
}

Cerebrovascular Diseases

Cerebrovasc Dis 2009;27:320-321

DOI: $10.1159 / 000202007$

\section{Deep Venous Thrombosis after Intracerebral Hemorrhage, Gender and Ethnicity: A Challenge for Therapeutic Approaches}

Gabriel R. de Freitas ${ }^{\mathrm{a}}$, Masao Nagayama ${ }^{\mathrm{b}}$

a Service of Neurology, Universidade Federal Fluminense, Rio de Janeiro, Brazil; bepartments of Neurology and Neurointensive Care, Yokohama Stroke and Brain Center, Yokohama, Japan

Primary intracerebral haemorrhage (ICH) is estimated to affect over 1 million people worldwide each year [1] and is associated with the highest mortality rate, with a 1-month case fatality of $42 \%$ [2]. The incidence of ICH is higher in certain populations, including blacks/African Americans and Asians. Up to $40 \%$ of strokes in China are hemorrhagic [3], and ICH represented 30\% of strokes in one Japanese study [4]. Although the higher prevalence in blacks is attributed to hypertension, the reason for the excess of ICH in Asians is disputable (e.g. hypertension, low serum cholesterol, higher prevalence of alcohol use).

Venous thromboembolism is an important cause of morbidity and mortality for patients in critically ill conditions. Without venous thromboembolism prophylaxis, up to $75 \%$ of patients with hemiplegia after stroke develop deep-vein thrombosis (DVT). Pulmonary embolism diagnosed at autopsy is present in a substantial proportion of patients with fatal stroke and accounts for about $10 \%$ of deaths after stroke, but is clinically evident in less than $2 \%$ of patients [5]. Patients with ICH may in fact be at higher risk for DVT than ischemic stroke patients [6]. A retrospective cohort study revealed a relative risk for clinical DVT after ICH of 4.0 (1.8 vs. $0.4 \%$ ) [7]. The relative risk for pulmonary embolism was 3.5 (0.4 vs. $0.1 \%$ ). Data comparing patients with ICH included in the International Stroke Trial with ischemic stroke patients also suggest an increased risk of clinical pulmonary embolism 1.3 versus $0.7 \%(p=0.06)$ - even after controlling for severity of the disease [8].

In this issue of the journal, Kawase et al. [9] report on the prevalence and variables associated with DVT in 81 Japanese patients with acute $\mathrm{ICH}$. Using duplex ultrasonography, they found that, at 2 weeks, $21 \%$ of patients had DVT and that female sex was the only independent predictor for DVT, contrary to the findings from western countries. It is worth mentioning that neither intermittent pneumatic compression nor heparin were used. Patients with paralysis involving the legs were required to wear belowknee elastic stockings.
The authors speculate that the excess of DVT in women may be caused by the use of oral contraceptives or hormone replacement therapy, decreased muscle pumping, variations in hormone concentration, obesity and genetic features. The incidence of DVT in this study was much higher than the $3 \%$ of DVT in the placebo group of the Factor Seven for Acute Hemorrhagic Stroke trial [10], but in line with another recent Japanese study, in which DVT was detected in $40.4 \%$ of patients with ICH after 2 weeks [11]. Differences in the ratio of complications between randomized clinical trials and the real world scenario could explain this discrepancy; however, in one report from a tertiary care center in the USA, the incidence of DVT was only $1.1 \%$ [12]. Although an alternative explanation for this excessive frequency of DVT may be less intense prophylactic measures in Asian patients, a recent study showed that Asians had a strong trend toward a higher risk of DVT (odds ratio $=3.22, \mathrm{p}=0.09$ ) than Caucasians [13].

Analysis of the Antithrombotic Trialists' Collaboration database disclosed that mechanical compression methods reduced the risk of DVT by about two thirds when used as monotherapy and by about half when added to a pharmacological method [14]. These benefits were similar irrespective of the particular method used (graduated compression stockings, intermittent pneumatic compression or foot pumps). Despite the existence of several clinical trials of DVT prevention in ischemic stroke, only two trials addressed the prophylaxis of DVT after ICH $[15,16]$. A doubleblind randomized phase IV trial has started, assessing the safety and efficacy of enoxaparin (starting 24-48 h after the onset of $\mathrm{ICH}$ ) in the prevention of venous thromboembolism [17]. Unfortunately, none of the trials above involved Asians.

Based on the few randomized clinical trials mentioned above, international guidelines suggest that patients with acute primary ICH and hemiparesis/hemiplegia should have intermittent pneumatic compression for the prevention of DVT (class I or grade $1 \mathrm{~B}$ recommendation) [18-20]. Optionally, after documentation of cessation of bleeding, low-dose subcutaneous low-molecular-weight heparin or unfractionated heparin may be considered in patients with hemiplegia after 2-4 days from onset (class $\mathrm{IIb}$, grade $2 \mathrm{C}$ recommendation). Whether the safety of heparin in the acute phase of ICH can be extrapolated to Asians is unknown.

Finally, the study of Kawase et al. [9] teaches us three important lessons: (1) DVT is common after ICH, and some patient characteristics (e.g. female sex, Asians) may put them in a higher risk category; (2) randomized clinical trials are needed and must include Asians, and (3) in the meanwhile, all ICH patients with hemiparesis/hemiplegia should receive intermittent pneumatic compression from the first day of admission, until the highestlevel evidence for standardization of the prophylaxis and acute management of DVT is obtained.

\section{KARGER}

Fax +41 613061234 E-Mail karger@karger.ch www.karger.com
(อ) 2009 S. Karger AG, Base

1015-9770/09/0274-0320\$26.00/0 


\section{References}

1 Qureshi AI, Tuhrim S, Broderick JP, Batjer HH, Hondo H, Hanley DF: Spontaneous intracerebral hemorrhage. N Engl J Med 2001;344:14501460.

2 Dennis MS: Outcome after brain haemorrhage. Cerebrovasc Dis 2003; 16(suppl 1):9-13.

-3 Zhang LF, Yang J, Hong Z, Yuan GG, Zhou BF, Zhao LC, Huang YN Chen J, Wu YF; Collaborative Group of China Multicenter Study of Cardiovascular Epidemiology: Proportion of different subtypes of stroke in China. Stroke 2003;34:2091-2096.

-4 Suzuki K, Kutsuzawa T, Takita K, Ito M, Sakamoto T, Hirayama A, Ito T, Ishida T, Ooishi H, Kawakami K: Clinico-epidemiologic study of stroke in Akita, Japan. Stroke 1987;18:402-406.

5 Wijdicks EF, Scott JP: Pulmonary embolism associated with acute stroke. Mayo Clin Proc 1997;72:297-300.

-6 André C, de Freitas GR, Fukujima MM: Prevention of deep venous thrombosis and pulmonary embolism following stroke: a systematic review of published articles. Eur J Neurol 2007;14:21-32.

7 Gregory PC, Kuhlemeier KV: Prevalence of venous thromboembolism in acute hemorrhagic and thromboembolic stroke. Am J Phys Med Rehabil 2003;82:364-369.

8 Cohen D, Lewis S, Sandercock P: Frequency of death, dependency and pulmonary embolism after haemorrhagic stroke. Cerebrovasc Dis 2000;10(suppl 2):52 (abstract).

-9 Kawase K, Okazaki S, Toyoda K, Toratani N, Yoshimura S, Kawano H, Nagatsuka K, Matsuo H, Naritomi H, Minematsu K: Sex difference in the prevalence of deep-vein thrombosis in Japanese patients with acute intracerebral hemorrhage. Cerebrovasc Dis 2009;27:313-319.

10 Mayer SA, Brun NC, Begtrup K, Broderick J, Davis S, Diringer MN, Skolnick BE, Steiner T; FAST Trial Investigators: Efficacy and safety of recombinant activated factor VII for acute intracerebral hemorrhage. N Engl J Med 2008;358:2127-2137.

- 11 Ogata T, Yasaka M, Wakugawa Y, Inoue T, Ibayashi S, Okada Y: Deep venous thrombosis after acute intracerebral hemorrhage. J Neurol Sci 2008;272:83-88.

12 Goldstein JN, Fazen LE, Wendell L, Chang Y, Rost NS, Snider R, Schwab K, Chanderraj R, Kabrhel C, Kinnecom C, Fitzmaurice E, Smith EE, Greenberg SM, Rosand J: Risk of thromboembolism following acute intracerebral hemorrhage. Neurocrit Care 2008, E-pub ahead of print.

13 Christensen MC, Dawson J, Vincent C: Risk of thromboembolic complications after intracerebral hemorrhage according to ethnicity. Adv Ther 2008;25:831-841.
14 Roderick P, Ferris G, Wilson K, Halls H, Jackson D, Collins R, Baigent C: Towards evidence-based guidelines for the prevention of venous thromboembolism: systematic reviews of mechanical methods, oral anticoagulation, dextran and regional anaesthesia as thromboprophylaxis. Health Technol Assess 2005;9:iii-iv, ix-x, 1-78.

15 Boeer A, Voth E, Henze T, Prange HW: Early heparin therapy in patients with spontaneous intracerebral haemorrhage. J Neurol Neurosurg Psychiatry 1991;54:466-467.

16 Lacut K, Bressollette L, Le Gal G, Etienne E, De Tinteniac A, Renault A, Rouhart F, Besson G, Garcia JF, Mottier D, Oger E; Venous Intermittent Compression and Thrombosis Occurrence Related to Intracerebral Acute Hemorrhage Investigators: Prevention of venous thrombosis in patients with acute intracerebral hemorrhage. Neurology 2005; $65: 865-869$.

17 http://clinicaltrials.gov/ct2/show/NCT00699465.

18 Broderick J, Connolly S, Feldmann E, Hanley D, Kase C, Krieger D, Mayberg M, Morgenstern L, Ogilvy CS, Vespa P, Zuccarello M: Guidelines for the management of spontaneous intracerebral hemorrhage in adults - 2007 update: a guideline from the American Heart Association/American Stroke Association Stroke Council, High Blood Pressure Research Council, and the Quality of Care and Outcomes in Research Interdisciplinary Working Group. Stroke 2007;38:2001-2023.

19 Albers GW, Amarenco P, Easton JD, Sacco RL, Teal P: Antithrombotic and thrombolytic therapy for ischemic stroke: American College of Chest Physicians Evidence-Based Clinical Practice Guidelines (8th edition). Chest 2008;133(6 suppl):630S-669S.

20 Steiner T, Kaste M, Forsting M, Mendelow D, Kwiecinski H, Szikora I, Juvela S, Marchel A, Chapot R, Cognard C, Unterberg A, Hacke W: Recommendations for the management of intracranial haemorrhage. I. Spontaneous intracerebral haemorrhage. The European Stroke Initiative Writing Committee and the Writing Committee for the EUSI Executive Committee. Cerebrovasc Dis 2006;22:294-316 (erratum appears in Cerebrovasc Dis 2006;22:461).

Masao Nagayama, MD, PhD, FAAN, FJSIM

Departments of Neurology and Neurointensive Care

Yokohama Stroke and Brain Center

1-2-1, Takigashira, Isogo-ku

Yokohama 235-0012 (Japan)

Tel. +81 45753 2500, Fax +81 457532879

E-Mail nagay001@sj8.so-net.ne.jp 